\title{
Carbon Emissions Decomposition Analysis of Yangtze River Delta Area in China: 2001-2012
}

\author{
Q. Z. Zhao ${ }^{a, *}$, Q. Y. Yan ${ }^{b}$
}

School of Economics and Management, North China Electric \& Power University, Baoding 071003, P. R. China

azhaoqiaozhi2006@126.com, bqingyouyan@126.com

Keywords: Yangtze River Delta Area, carbon emissions, LMDI

\begin{abstract}
Based on the Intergovernmental Panel on Climate Change (IPCC) report, carbon emissions of Yangtze River Delta Area are calculated from 2001 to 2012. Based on LMDI method, aggregated carbon emissions in this area are decomposed into five effects: energy structure, energy intensity, industrial structure, economic output and population scale effects. The decomposition results reveal that of the five factors, energy output factor contributed most to carbon emissions (147.30\%), energy intensity was the most negative contributor (68.43\%). Population scale contributed $22.26 \%$. The energy structure and industrial structure contributed insignificantly, which reveals that structure adjustment is the potential factor to release their effects. Under the national strategy of the Yangtze River Delta region Regional planning (2009-2020), many opportunities maybe obtained for three provinces in this region. Regional integration can promote industrial structure adjustment better and avoid repeated construction and conquer internal industrial isomorphism. Spatial industrial layout will be optimized, i.e. Nucleus nine belt layouts, a core with two wings city groups strategy. Prior to developing modern service industry, strengthen advanced manufacturing industry, accelerate emerging industries development, consolidate and upgrade traditional industries. This policies not only will stimulate economic growth, but will bring structure adjustment to reduce energy consumption and cut down carbon emissions.
\end{abstract}

\section{Introduction}

Carbon emissions and associated greenhouse effects have triggered many global concerns. As a responsible country, China makes a promise that in 2020 carbon emission per GDP will be cut by $40 \% \sim 50 \%$ compared with that in 2005. As an important economic circle, Yangtze River Delta Area is the most prosperous region in China and occupies a large proportion in energy consumption and carbon emissions. Thus, it is of realistic significance to explore the influencing factors which drive carbon emissions growth. It shoulders a heavy task of mitigating $\mathrm{CO} 2$ emissions and it is necessary for this region to develop low carbon economy. Thus an investigation of the intrinsic driving factors is necessary for understanding its emissions reduction polices, realizing the low carbon development transformation and implementing sustainable development strategies. Yangtze River Delta Area (Yangtze Delta), which is centered on Shanghai and includes Jiangsu and Zhejiang provinces, is a region circle which is the densest population, the most developed economy, the highest urbanization and economy going up most quickly in China. Moreover this region is one of the most economic growing potential regions in China. Carbon emissions of this region increased with rapid rate and have brought out a series of environmental problems. An evaluation on carbon emissions trend should be considered with a comprehensive, accurate and complete aspect. On this 
basis, it is necessary to study on their influencing factors and to find the direction and space for effectively cutting carbon emissions and realizing low carbon economy transformation.

Many researchers have focused on Yangtze Delta Area carbon emission analysis (Cao Guangxi, 2015; Zhan Zhenghua, 2014; Ding Sheng, 2014; Zhai Shiyan, 2013; Hua Jian, 2012 et al) [1-5]. Decomposition analysis is an effective way to analyze influencing factors of carbon emissions in a region. Kaya (1989) decomposed carbon dioxide emissions into four factors: population, GDP per capita, energy intensity and energy structure which this method has been widely used to reveal driving effects and called Kaya identity [6]. According to Kaya identity, Ramirez (2005) used Kaya identity to analyze China, Japan, Europe and Global carbon emissions, and found population and economic development were the main factors [7]. Extended Kaya identity was used to decomposed carbon emissions of four European countries into nine factors and found carbon intensity, economic growth and population change were the main influencing factors. Hu Jinzhi (2008) analyzed China's carbon emission characters and the dynamic evolutions [8]. The Logarithmic Mean Divisia Index method (LMDI) is the most preferred decomposition method for the theoretical basis, zero residual, adaptability, result interpretation and other properties among decomposition methods (Ang B.W, 1996, 1997, 1999, 2000, 2004 and 2012)[9-14]. Many researchers (Wang, 2005; Guo, 2010; Tu, 2014; Wenwen Wang, 2014; Frédéric Branger, 2015) used LMDI method to explore the relative contributions quantitatively to the growth of energy consumption and carbon emissions [15-19].

Thus, this paper is trying to use LMDI to decompose Yangtze Delta Area carbon emissions during 2001-2012. It is organized as follows. In Section 2, we describe the methodology of this study. In Section 3, we will deeply analyze the main results in this region during 2001-2012. The last section will concludes this study and some suggestions are given to cut down its carbon emissions.

\section{Methodology and data description}

\subsection{The LMDI decomposition method}

LMDI is a widely used decomposition technique available in energy and environment literature. Ang argued that LMDI was the most preferred decomposition method for the theoretical basis, zero residual, adaptability, result interpretation and other properties among decomposition methods [9-14]. We will decompose Yangtze Delta Area carbon emissions by LMDI method from the following Kaya identity:

$$
\mathrm{C}=\frac{\mathrm{C}}{\mathrm{E}} \cdot \frac{\mathrm{E}}{\mathrm{GDP}} \cdot \frac{\mathrm{GDP}}{\mathrm{P}} \cdot \mathrm{P}
$$

where $\mathrm{C}$ denotes aggregated carbon emissions, $\mathrm{E}$ is the total energy consumption level, GDP is gross domestic product and $\mathrm{P}$ is the population scale. To further analyze categorized by industry sectors and energy types, Kaya identity is rewritten as Eq.(2):

$$
\mathrm{C}=\sum_{i, j} \frac{C_{i j}}{E_{i j}} \cdot \frac{E_{i j}}{E_{i}} \cdot \frac{E_{i}}{I_{i}} \cdot \frac{I_{i}}{G D P} \cdot \frac{G D P}{P} \cdot P=\sum_{i, j} C F_{i j} \cdot E S_{i j} \cdot E I_{i} \cdot Y S \cdot E Y \cdot P
$$

where subscript $\mathrm{j}$ denotes energy type and $\mathrm{i}$ denotes industry sector; $C_{i j}$ denotes carbon emissions quantity from energy $\mathrm{j}$ consumption by industry $\mathrm{i}\left(\mathrm{E}_{\mathrm{ij}}\right), E_{i}$ is total energy consumption quantity of industry $\mathrm{i}, I_{i}$ is the value added of industry $\mathrm{i} ; C F_{i j}=C_{i j} / E_{i j}$ denotes carbon emission coefficient of 
energy $\mathrm{j}$ in industry $\mathrm{i}, E S_{i j}=E_{i j} / E_{j}$ is the energy $\mathrm{j}$ consumption proportion of industry $\mathrm{i}$, which is called energy structure factor; $E I_{i}=E_{i} / I_{i}$ denotes energy intensity of industry i, which is named energy intensity factor; $Y S_{i}=I_{i} / G D P$ denotes the industry i value added proportion in GDP, which reveals industrial structure and named industrial structure factor, $E Y=G D P / P$ denotes economic output per capita in a period, which is called economic output factor. $C^{0}$ and $C^{t}$ denote total carbon emissions of a region in period 0 and period $\mathrm{t}$, respectively. $\Delta C^{t}$ is the change of $\mathrm{C}$ from period 0 to period t. Accordingly, $\Delta C^{t}$ can be decomposed into emission coefficient effect $\left(\Delta C_{C F}^{t}\right)$, energy structure effect $\left(\Delta C_{E S}^{t}\right)$, energy intensity effect $\left(\Delta C_{E I}^{t}\right)$, economic structure effect $\left(\Delta C_{Y S}^{t}\right)$, economic output effect $\left(\Delta C_{\mathrm{EY}}^{t}\right)$ and population scale effect $\left(\Delta C_{P}^{t}\right)$.

$$
\Delta C^{t}=C^{t}-C^{0}=\Delta C_{C F}^{t}+\Delta C_{E S}^{t}+\Delta C_{E I}^{t}+\Delta C_{Y S}^{t}+\Delta C_{E Y}^{t}+\Delta C_{P}^{t}
$$

Ang (1996) gave the formulas of LMDI method. When $\mathrm{V}=\mathrm{V}_{\mathrm{X} 1} \cdot \mathrm{V}_{\mathrm{X} 2} \cdots \mathrm{V}_{\mathrm{X} n}$ and its change $\Delta V_{\text {tot }}$ are considered, the additive form of LMDI (LMDI-I) is $\Delta \mathrm{V}_{\mathrm{tot}}=\Delta \mathrm{V}_{\mathrm{X} 1}+\Delta \mathrm{V}_{\mathrm{X} 2}+\cdots+\Delta \mathrm{V}_{\mathrm{X} n}$ and the calculation formula is $\Delta \mathrm{V}_{\mathrm{Xk}}=\sum_{i} \ln \left(X_{k, i}^{T} / X_{k, i}^{0}\right) \cdot L\left(V_{i}^{T}, V_{i}^{0}\right)$. He further suggested analytical limit to handle with zero values. Thus $L(a, b)=(b-a) /(\ln b-\ln a), L(a, a)=a(a \neq 0)$ and $L(a, b)=0(a b=0)$. Applying LMDI additive method, the carbon emission factors can be decomposed as Eq.(4):

$$
\begin{aligned}
\Delta C^{t} & =\sum_{i, j} L\left(C_{i j}^{t}, C_{i j}^{t-1}\right) \ln \left(\frac{C F_{i j}^{t}}{C F_{i j}^{t-1}}\right)+\sum_{i, j} L\left(C_{i j}^{t}, C_{i j}^{t-1}\right) \ln \left(\frac{E S_{i j}^{t}}{E S_{i j}^{t-1}}\right)+\sum_{i, j} L\left(C_{i j}^{t}, C_{i j}^{t-1}\right) \ln \left(\frac{E I_{i}^{t}}{E I_{i}^{t-1}}\right) \\
& +\sum_{i, j} L\left(C_{i j}^{t}, C_{i j}^{t-1}\right) \ln \left(\frac{Y S_{i}^{t}}{Y S_{i}^{t-1}}\right)+\sum_{i, j} L\left(C_{i j}^{t}, C_{i j}^{t-1}\right) \ln \left(\frac{E Y_{t}}{E Y_{t-1}}\right)+\sum_{i, j} L\left(C_{i j}^{t}, C_{i j}^{t-1}\right) \ln \left(\frac{P_{t}}{P_{t-1}}\right)
\end{aligned}
$$

Because there is little change in years of carbon emission coefficients of energy types and it is difficult to measure these coefficients in technology, we assume they are constant and we use as emission coefficients given by IPCC 2008. Thus in LMDI, we have $\ln \left(C F_{i t} / C F_{i 0}\right)=0$ and $\Delta C_{C F}^{t}=0$ by Eq.(3). And this paper only considers the latter five factors.

\subsection{Data sources and description}

The study period in this paper is 2001-2012. Energy consumption in this paper is final energy consumption which considers eight energy types: coal, coke, crude oil, fuel oil, gasoline, kerosene, diesel oil and natural gas. Electricity includes thermal power, hydropower, nuclear power and other sources. Although thermal power releases carbon, its generation consumes coal. Thus to avoid repeated calculation, electricity and heat energy is excluded. Economic output is categorized from 
six industry sectors: i) Primary industry: farming, forestry, animal husbandry, fishery and water conservancy; ii) Industry; iii) Construction; iv)Tertiary industry. Residential energy consumption is excluded in this paper.

The energy consumption data are total final consumption quantity in 2001-2012, which are from China Statistical Yearbook and China Energy Statistical Yearbook for 2001-2012 [20-21]. They are in physical quantity, the former seven energy types units are $10^{4}$ tons $(\mathrm{t})$ and the natural gas unit is $10^{8} \mathrm{~m}^{3}$. They are in different units and we convert them into standard coal consumption quantity in $10^{4}$ tsc (tsc: tons standard coal). The converting coefficients for different energy into standard coal come from national standard GB/T 2589-2008, "General Rules for Comprehensive Energy Consumption Calculation" [22]. The coefficients for coal, coke, crude oil, fuel oil, gasoline, diesel oil, kerosene and natural gas are 0.7143 tsc/ton, 0.9710 tsc/ton, 1.4286 tsc/ton, 1.4286 tsc/ton, $1.4714 \mathrm{tsc} / \mathrm{ton}, 1.4571 \mathrm{tsc} / \mathrm{ton}, 1.4714 \mathrm{tsc} / \mathrm{ton}, 13.30 \mathrm{tse} / 10^{4} \mathrm{~m}^{3}$, respectively. The carbon emission coefficients are from IPCC (2008)[23]. Coefficients for raw coal, coke, crude oil, fuel oil, gasoline, diesel oil , kerosene and natural gas are $0.755910^{4} \mathrm{t} / 10^{4} \mathrm{tsc}, 0.855010^{4} \mathrm{t} / 10^{4} \mathrm{tsc}, 0.58610^{4} \mathrm{t} / 10^{4} \mathrm{tsc}$, $0.61910^{4} \mathrm{t} / 10^{4} \mathrm{tsc}, 0.55410^{4} \mathrm{t} / 10^{4} \mathrm{tsc}, 0.59210^{4} \mathrm{t} / 10^{4} \mathrm{tsc}, 0.57110^{4} \mathrm{t} / 10^{4} \mathrm{tsc}, 0.44810^{4} \mathrm{t} / 10^{4} \mathrm{tsc}$, respectively[23]. Data on GDP, sectional values added, population data are from China Statistical Yearbook, Shanghai Statistical Yearbook, Jiangsu Statistical Yearbook and Zhejiang Statistical Yearbook for the appropriate periods [24-26]. GDP, value added of each sub-sector are converted into 2000 constant prices. GDP is measured in billion yuan and population in billion. Population scale is calculated by the average value of adjacent years.

\section{Results and discussion}

\subsection{Overall effects analysis}

Using Eq.(4), we calculated the energy structure effect, energy intensity effect, industry structure effects, economic output effect and population scale effect due to energy consumption in Yangtze Delta Area during 2001-2012. Results are shown in Table 1.

Table 1: Decomposition results of Yangtze Delta Area during 2001-2012(unit: $10^{4}$ ton)

\begin{tabular}{ccccccc}
\hline Year & $\Delta \mathrm{ES}$ & $\Delta \mathrm{EI}$ & $\Delta \mathrm{YS}$ & $\Delta \mathrm{EY}$ & $\Delta \mathrm{P}$ & Total \\
\hline 2001 & -55.46 & -792.12 & 0.07 & 473.45 & 88.69 & -285.39 \\
2002 & 48.99 & -71.25 & 0.58 & 640.12 & 19.21 & 637.64 \\
2003 & -29.47 & -397.94 & 0.95 & 768.90 & 50.32 & 392.77 \\
2004 & 12.70 & 921.65 & -0.01 & 955.26 & 66.06 & 1955.66 \\
2005 & 27.34 & 387.87 & -0.50 & 1036.40 & 118.13 & 1569.24 \\
2006 & 18.07 & -724.18 & 0.02 & 1209.03 & 166.36 & 669.31 \\
2007 & -24.69 & -668.20 & -0.26 & 1404.57 & 153.32 & 864.74 \\
2008 & -21.56 & -634.71 & -1.88 & 1126.69 & 139.99 & 608.52 \\
2009 & 24.37 & -992.85 & -2.72 & 1105.01 & 119.44 & 253.25 \\
2010 & 0.06 & -925.58 & -0.55 & 1041.52 & 397.77 & 513.21 \\
2011 & -14.09 & -245.11 & -1.72 & 875.84 & 386.78 & 1001.70 \\
2012 & -67.84 & -1318.13 & -1.95 & 1116.48 & 70.13 & -201.32 \\
\hline
\end{tabular}

Table 1 reveals that energy intensity contributed negatively to carbon emissions except 2004 and 2005. Economic output and population scale contributed positively. Energy structure and industrial structure had positive or negative effect on carbon emissions during this period. From contribution ratio, Fig.1 reveals that energy intensity, economic output and population scale had significant effect, while energy structure and industrial structure had insignificant effect on carbon emissions. Energy structure accumulatively contributed $-1.02 \%$ to total accumulated carbon emissions during 
2001-2012, energy intensity contributed $-68.43 \%$ to total carbon emissions change from 2001 to 2012. Industrial structure contributed accumulatively $-0.10 \%$ to total change. Economic output contributed $147.30 \%$ and population contributed $22.26 \%$ totally from 2001 to 2012 .Thus we can conclude that economic output was the most driving factor which led to carbon emissions growing quickly. Population scale is the second order driving factor from accumulated effects. Energy intensity was the inhibitoriest factor which made carbon emissions decreasing. The energy structure and industrial structure factors didn't released significantly with accumulated contribution ratio $-1.02 \%$ and $-0.10 \%$.

\subsection{Energy structure effect}

Table 1 reveals that energy structure didn't affect carbon emissions significantly during 2001-2012 in Yangtze Delta Area. In 2002-2011, the carbon emissions in this region were increasing which energy structure had a decreasing contribution ratio. It affected carbon emissions positively or negatively. In 2012 , the aggregated carbon emissions decreased $201.32 \times 10^{4}$ tons which energy structure factor led to a decrease of $67.84 \times 10^{4}$ tons. Why this factor didn't play an effective role? We assessed the energy consumption proportion for eight different energy types (Fig.2). Coal and coke emission coefficients $(0.7559,0.8550)$ are greater than each of other energy types and we named them high-carbon energy. Coefficients of other energy types are much less than coal and coke which we call them low-carbon energy. Fig. 2 reveals that coal was the main energy consumption which the proportion decreased from $48.26 \%$ in 2001 to $34.29 \%$ in 2012. It also reveals that coke proportion increased from $9.56 \%$ in 2001 to $20.78 \%$ in 2012 . Although coal proportion decreased 14 percents, coke proportion increased 11 percents. The low-carbon emission energy proportion almost remained unchanged from 42.18\% in 2001 to $44.39 \%$ in 2012. Above data means that coke was the main alternative energy of coal. As high-carbon energy types, coke coefficient was larger than that of coal which can explain why this energy substitution did not led to carbon emissions decreasing during 2001-2012. It also gives us information that if we will cut down carbon emissions by improving energy structure, we should use low-carbon energy types to substitute high-carbon energy types. Only by this substitution, energy structure factor can bring significantly negative effects.

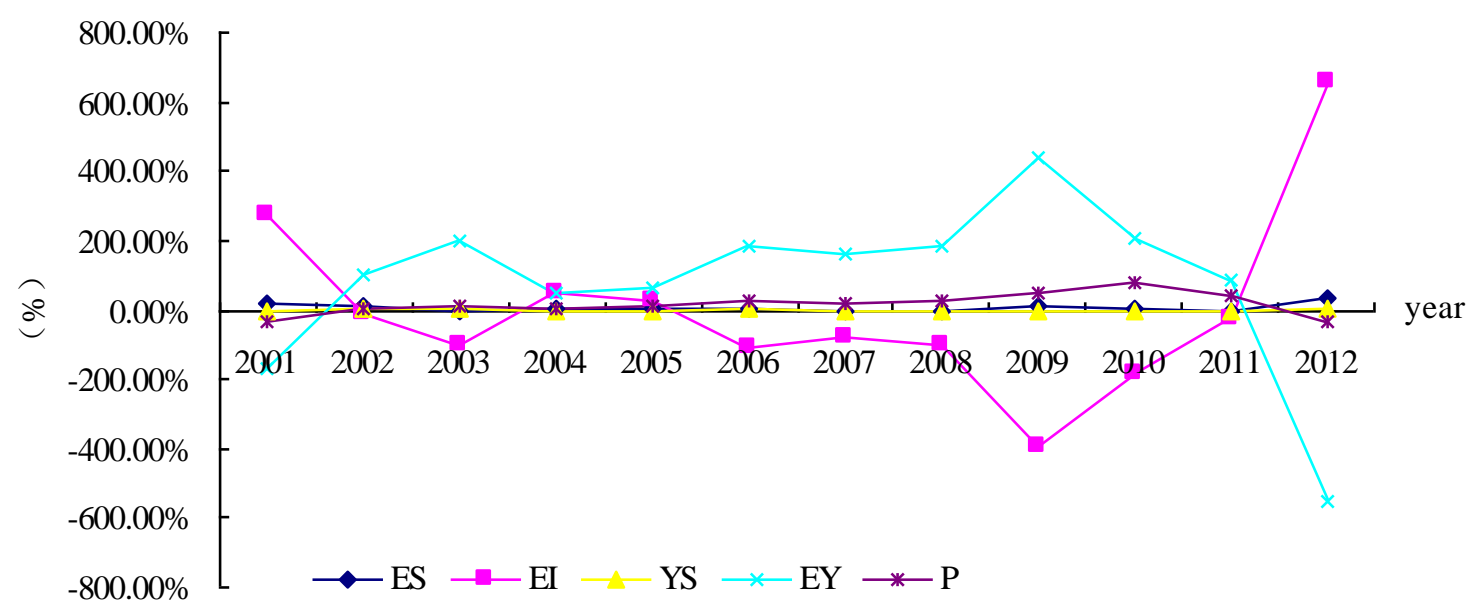

Fig.1. Contribution ratio of factors during 2001-2012. 


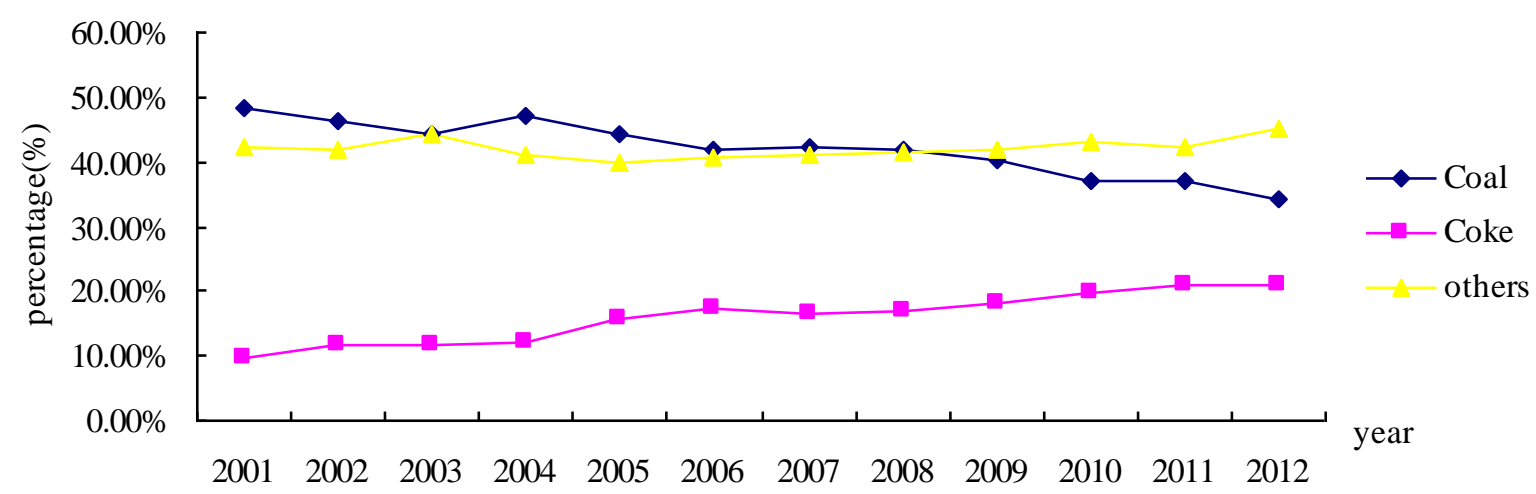

Fig.2. Energy consumption proportion in Yangtze Delta Area during 2001-2012

\subsection{Energy intensity effect}

Table 1 reveals that energy intensity factor made a negative contribution to carbon emission in Yangtze Delta Area except in 2004 and 2005. It is the inhibitoriest factor which led to carbon emissions decreasing. Fig.1 reveals that its inhibitory effect on carbon emissions was rising. The energy intensity reflects the overall efficiency of energy and economic activity. A decrease in energy intensity usually indicates an improvement in energy efficiency from technological progress. Runar (2007) argued that energy rebound effect existed [27]. Energy intensity made a negative effect proves that technology progress restrained carbon emissions' growth and there was no significant energy rebound effect. However, in 2004-2005, energy intensity made a positive effect on carbon emissions. During this period, coal price increased sharply from 206 yuan per ton in 2004 to 270 yuan per ton in 2005 , which increased by $30 \%$. On one side, technological progress made energy efficiency improve and energy demand decrease; on the other side, technological progress brought economic growth and led to energy demand increasing. The two effect are offset which led to insignificantly positive effect on carbon emissions in 2004-2005.

Fig.3 reveals that Shanghai and Zhejiang energy consumption proportion were decreasing while Jiangsu energy consumption proportion was increasing from $37 \%$ in 2001 to $50 \%$ in 2012 . Shanghai energy proportion decreased from $31 \%$ in 2001 to $23 \%$ in 2012. Fig.4 reveals that energy intensity of three provinces was all decreasing, but the Zhejiang was the quickest and Shanghai was the slowest. This can explain why energy intensity had a significant effect on carbon mitigating.

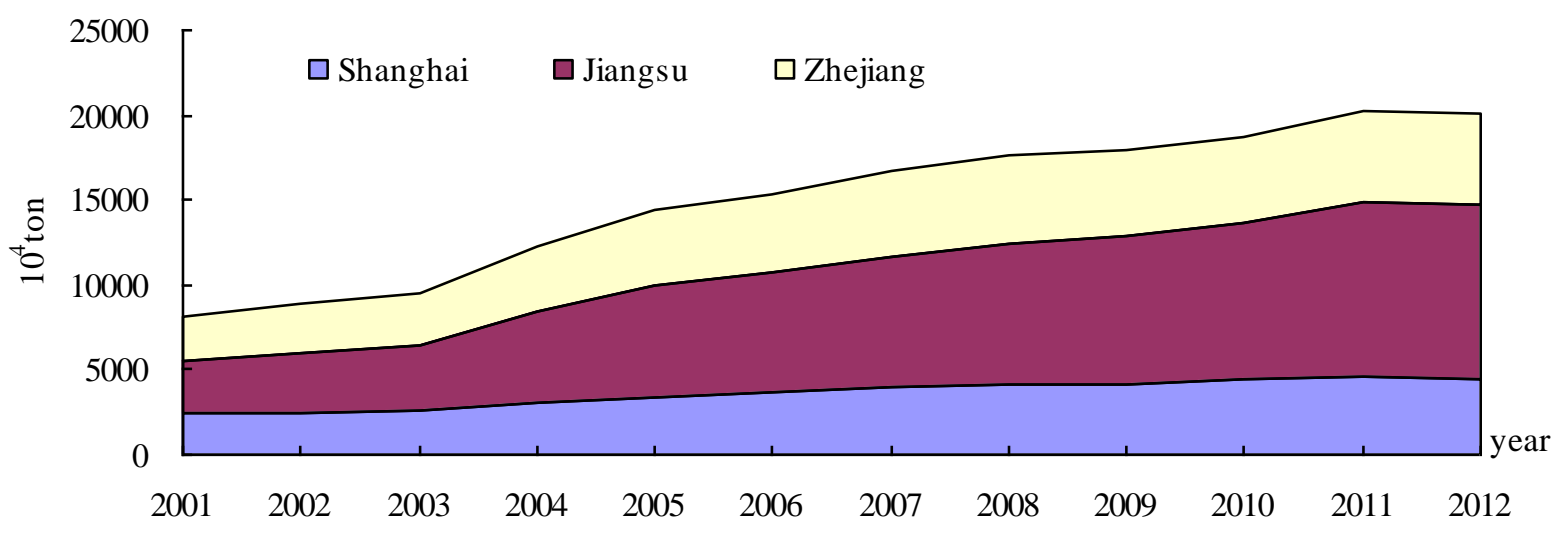

Fig.3. Provincial energy consumption in Yangtze Delta Area in 2001-2012 

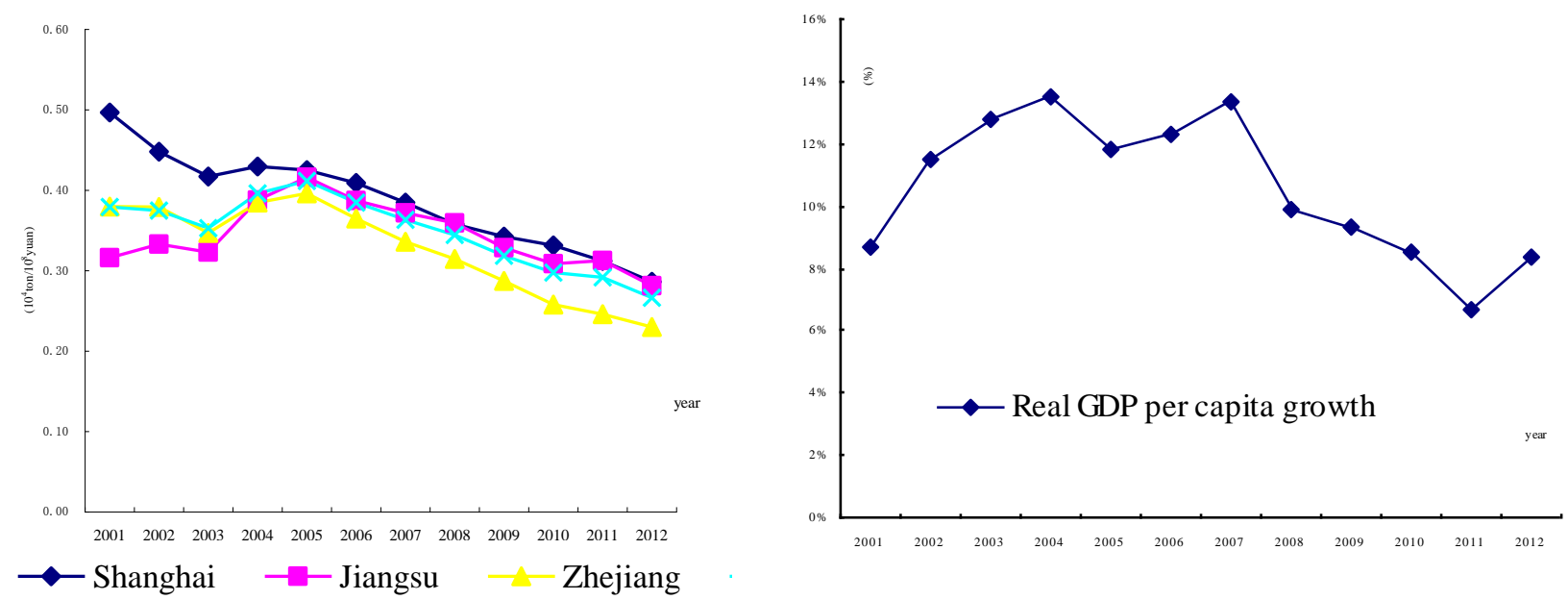

Fig.4. Provincial energy intensity in 2001-2012. Fig.5. Real per capita GDP growth in 2001-2012. 3.4 Industrial structure effect

Table 1 reveals that industrial structure had a positive effect on carbon emissions in 2001-2003, 2006 and had a negative effect in 2004-2005, 2007-2012. Fig.1 reveals that industrial structure had an insignificant effect on carbon emissions. It means industrial structure didn't bring effective carbon mitigation. During the $12^{\text {th }}$ five-year plan (2011-2015), China economy focuses on industrial structure adjustment and remains steady economic growth while how to release the negative effect of industrial structure is a heavy task for China. As the most prosperous region in China, this task is tougher than other areas. Fig.5 reveals that industry was the most proportion in four industrial sectors, service industry was in the second order which its proportion increased from.

Table 2: Industrial value added in GDP of Yangtze Delta Area in 2001-2012(unit: \%)

\begin{tabular}{ccccc}
\hline Year & First Industry & Industry & Construction Industry & Service Industry \\
\hline 2001 & $9.15 \%$ & $45.47 \%$ & $5.83 \%$ & $39.54 \%$ \\
2002 & $9.16 \%$ & $45.48 \%$ & $5.83 \%$ & $39.53 \%$ \\
2003 & $9.19 \%$ & $45.49 \%$ & $5.83 \%$ & $39.49 \%$ \\
2004 & $9.19 \%$ & $45.49 \%$ & $5.83 \%$ & $39.48 \%$ \\
2005 & $9.24 \%$ & $45.50 \%$ & $5.85 \%$ & $39.42 \%$ \\
2006 & $9.26 \%$ & $45.50 \%$ & $5.85 \%$ & $39.38 \%$ \\
2007 & $9.26 \%$ & $45.50 \%$ & $5.85 \%$ & $39.39 \%$ \\
2008 & $9.30 \%$ & $45.50 \%$ & $5.86 \%$ & $39.34 \%$ \\
2009 & $9.35 \%$ & $45.49 \%$ & $5.88 \%$ & $39.28 \%$ \\
2010 & $9.38 \%$ & $45.50 \%$ & $5.89 \%$ & $39.23 \%$ \\
2011 & $9.42 \%$ & $45.50 \%$ & $5.90 \%$ & $39.18 \%$ \\
2012 & $9.45 \%$ & $45.50 \%$ & $5.91 \%$ & $39.14 \%$ \\
\hline
\end{tabular}

Table 2 reveals that there was little change in industrial value added proportion which meant little industrial adjustment during 2001-2012. This may explain the reason for insignificant effect of YS on carbon emissions in this period. Shanghai takes the center in Yangtze Delta Area and Jiangsu, Zhejiang develops cooperatively. This area is lack of natural resources and its development in the future should focus on non-energy intensive industries, such as service industries. According to Yangtze Delta Area regional planning (2009-2020), Shanghai will develop priory to modern service and advanced manufacturing industry. Meanwhile, Jiangsu and Zhejiang centered Shanghai, upgrading their traditional industries and promote industrial structure adjustment. 


\subsection{Economic output effect}

Real GDP per capita comprehensively reflects the production capacity in a region. Table 1 reveals economic output was the most driving factor, which accumulatively contributed $147.30 \%$ to carbon emissions during 2001-2012. There was a decrease in GDP per capita growth rate after 2008, while its contribution ratio absolute value was rising. It means that economic development was always the main factors which promote this region carbon emissions growth and it had the most effect on carbon emissions. The driving effect was more and more significant, with increasing trend. Energy, as the basic production element in production, supports economic development. Extensive economic development mode led to much dependence on energy consumption than intensive economic development mode. With quick economic growth and quick urbanization, energy demand grew quicker than before and led to more energy consumption which contributed carbon emissions more. Under this background, for Yangtze Delta Area, the transformation from extensive economic mode to intensive mode is more necessary than other areas. Because this region lack of natural resources, north coal transport project led to coal cost rose dramatically which increased energy cost and drag off GDP growth. Global energy price fluctuations in recent years had made China's GDP growth rate decrease and the Yangtze Delta Area was also the same as whole economy in China. On the premise of keeping stable economic growth rate, to accelerate economic transition pace maybe can decrease the dependence degree of energy demands and relieve the driving effect on carbon emissions.

\subsection{Population scale effect}

Population scale effect was always had the same direction as carbon emissions change. When carbon emissions grew, population scale had a positive effect. When carbon emissions decreased in 2001 and 2012, it had a negative contribution to carbon emissions. Its accumulated contribution ratio from 2001 to 2012 is $22.26 \%$ and it is the secondary driving factors during 2001-2012. Fig.6 reveals that Yangtze Delta Area's GDP per capita was much more than that of China. It led to large population inflow into Yangtze Delta Area which made population grew quicker than other regions. It accelerated residential energy consumption and brought more carbon emissions growth.

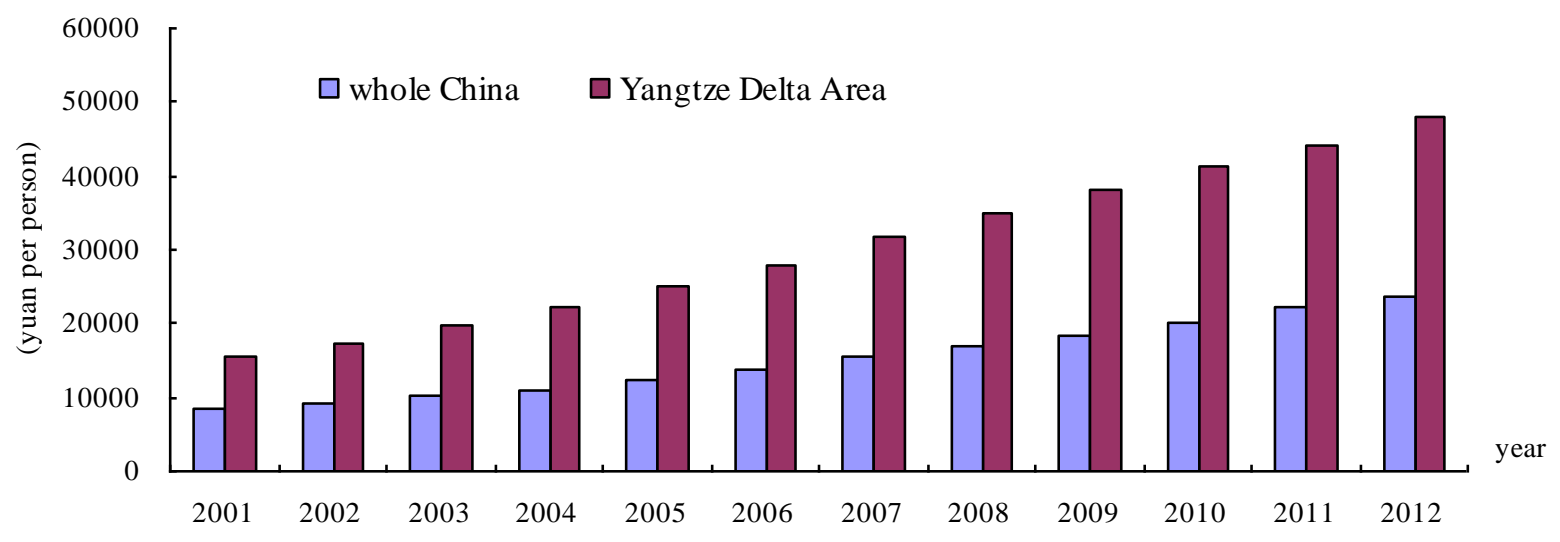

Fig.6. A comparison of EY between whole China and Yangtze Delta Area

\section{Conclusions}

The objective of this study is to identify the significant driving and inhibitory factors for Yangtze Delta Area and to explore developing suggestions for carbon mitigation. In the national strategy of the Yangtze River Delta region Regional planning (2009-2020), this area will be targeted as advanced manufacturing center, world city group and important Asia Pacific port. With 
implementing this planning, many opportunities for this area will be obtained whether for economic development or environmental protection.

By applying LMDI, we find out that economic output was the first driving factors which contributed $147.30 \%$ accumulatively from 2001 to 2012. Energy intensity was the main negative factors which led to carbon mitigation in Yangtze Delta Area. Population scale contributed 19.83\% to carbon emissions growth. Energy structure and industrial structure factors didn't contribute significantly during this period. As another national regional integration region, Jing-Jin-Ji region is also facing heavy task of cutting down carbon emissions and transforming economic growth mode. Fig.7 made a comparison of carbon emissions decomposition results between Yangtze Delta Area and Jing-Jin-Ji region. Fig.7 reveals that economic output was more positive contributive in Yangtze Delta Area than that in Jing-Jin-Ji region, while energy intensity factor had a more negative contribution in Yangtze Delta Area than that in Jing-Jin-Ji region. It reveals that though Yangtze have more technology advantages than that of Jing-Jin-Ji, the economic output growth led to more carbon emissions growth. Fig.8 compared the carbon change annually in two regions. We can find that before 2005 Yangtze Delta Area had more increment of carbon emissions and after that Yangtze Delta Area increased less than Jing-Jin-Ji region. Even in 2012, carbon emissions of Yangtze Delta began to decrease. Regional integration can promote industrial structure adjustment better and avoid repeated construction and conquer internal industrial isomorphism. Spatial industrial layout will be optimized, i.e. Nucleus nine belt layouts, a core with two wings city groups development strategy. Prior to developing modern service industry, strengthen advanced manufacturing industry, accelerate emerging industries development, consolidate and upgrade traditional industries.

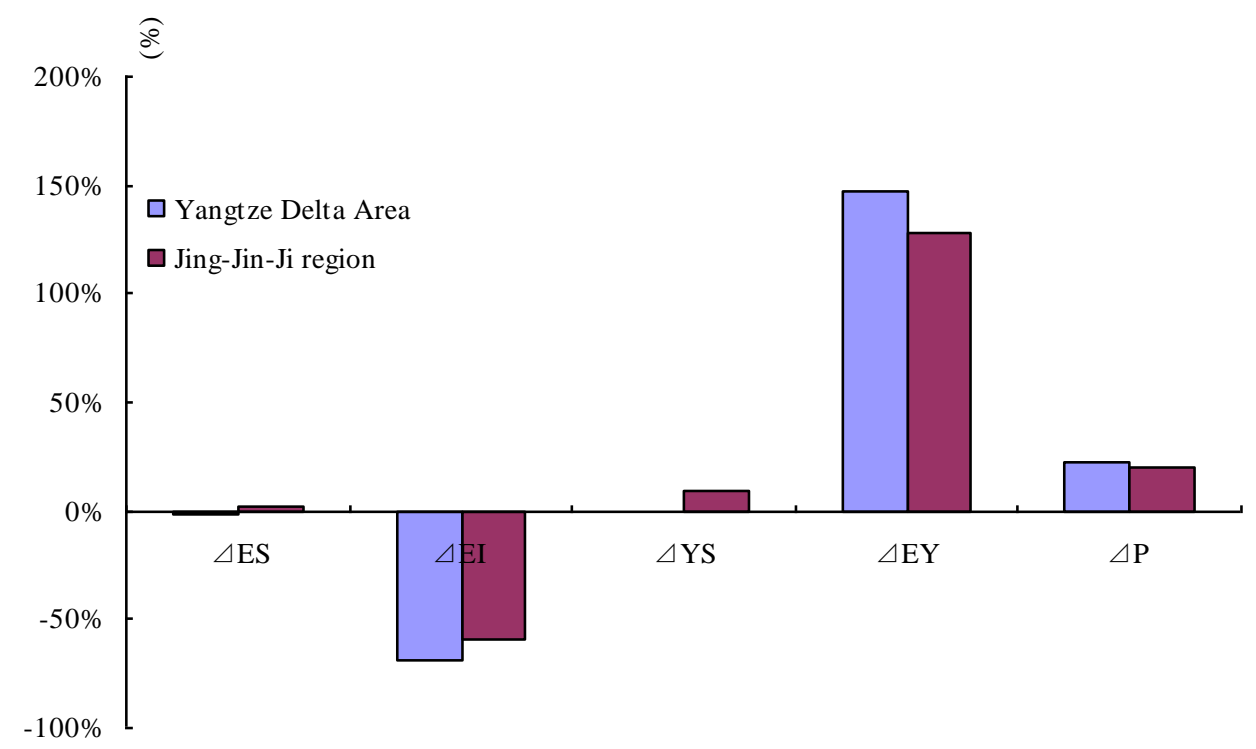

Fig.7. Factor contribution comparison between Yangtze Delta Area and Jing-Jin-Ji region 


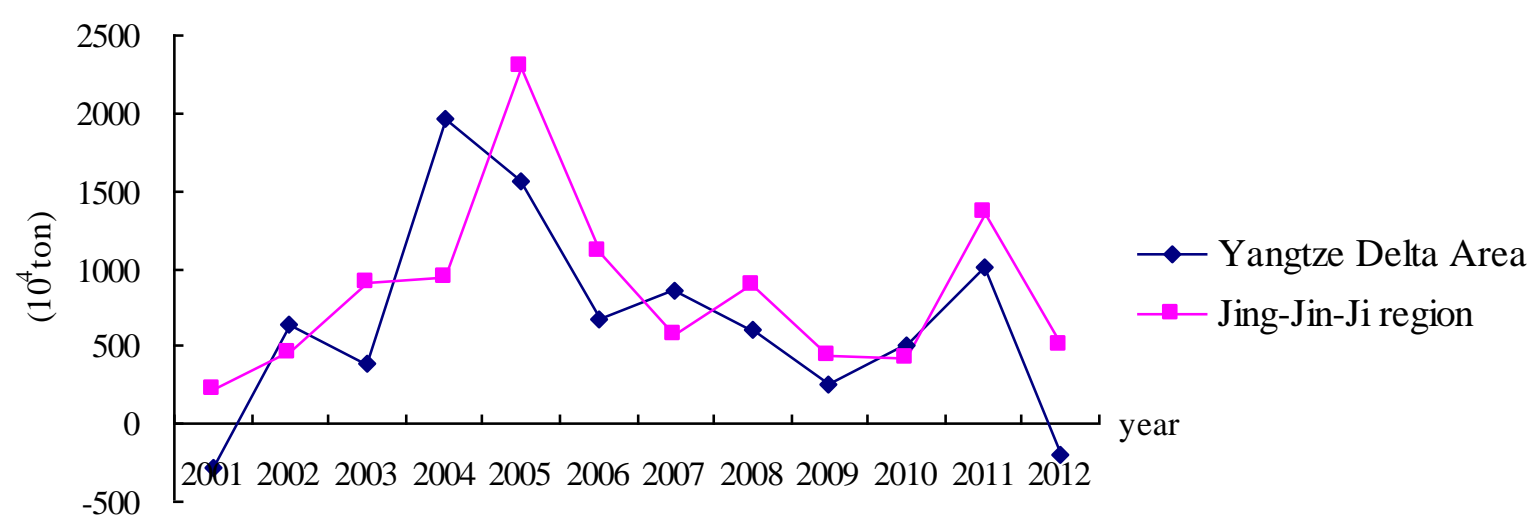

Fig.8 Carbon emissions comparison between Yangtze Delta Area and Jing-Jin-Ji region

Acknowledgements: This work was financially supported by the Fundamental Research Funds for the Central Universities (Grant nos.9160613012) and Philosophy and Social Science Research Base of Hebei Province.

\section{References}

[1] Cao Guangxi, Liu Yuqiao and Zhou Yang, Study on carbon emission decoupling of the manufacturing industry in Yangtze River Delta Area, Yuejiang Academic Journal, 2015,2, 37-44.

[2] Zhan Zhenghua, Cai Shiqiang, A study on the relationship among FDI, economic growth and $\mathrm{CO}_{2}$ emission in the Yangtze River Delta region, Commercial Research, 2014, 4, 36 -56.

[3] Ding Sheng, Wen Zuomin, Analysis of factors affecting carbon emission in Yangtze River Delta Area based on IPAT, Technoeconomics \& Management, 2014, 9, 15-20.

[4] Zhai Shiyan, Wang Zheng, Modeling relationship among carbon emission, energy consumption and economic growth by ARDL in the Yangtze River Delta, Resources and Environment in the Yangtze Basin, 2013, 22 (1), 94-103.

[5] Hua Jian, Ren Jun, Measurement, comparison and impact factors of carbon emissions in Yangtze River Delta region between 1990-2009, Journal of Hohai University(Philosophy and Social Sciences), 2012,14(3), 57-61.

[6] Kaya Yoichi, Impact of carbon dioxide emission on GNP growth: Interpretation of proposed scenarios, Presentation to the Energy and Industry Subgroup, Response Strategies Working Group, IPCC, Paris, 1989.

[7] C A Ramirez, M Patel, K Block, The non-energy intensive manufacturing sector: an energy analysis relating to the Netherlands, energy, 2005, 30, 749-767.

[8] Hu Jinzhi, Huang Xianjin etal, Characteristics and dynamic evolution of carbon emissions in China, China Population, Resources and Environment, 2008,3, 15-19.

[9] Ang B.W. and Lee, P.W.: 'Decomposition of industrial energy consumption: the energy coefficient approach'. Energy Economics, 1996, 18, 129-143.

[10] Ang B.W., Choi, K.H.: 'Decomposition of aggregate energy and gas emissions intensities for industry: a refined Divisia index method'. Energy, 1997, 18, 59-73.

[11] Ang B.W. : 'Decomposition methodology in energy demand and environmental analysis', In: vanden Bergh, J.C.J.M. (Ed.), Handbook of Environmental and Resource Economics. Edward Elgar Publishers, Cheltenham, 1999.

[12] Ang B.W. and Zhang, F.Q.: 'A survey of index decomposition analysis in energy and 
environmental studies', Energy, 2000, 25, 1149-1176.

[13] Ang B.W: 'Decomposition analysis for policy making in energy: which is the preferred method?', Energy Policy. 2004, 32, 1131-1139.

[14] Su B and Ang B.W: 'Structural decomposition analysis applied to energy and emissions: some methodological developments', Energy Economics, 2012, 34,177-188.

[15] Wang C, Chen J and Zhou J: 'Decomposition of energy-related co2 emissions in China: 19572000', Energy, 2005, 30(1), 73 - 83.

[16] Guo Chao-xian: 'Decomposition of China's carbon emissions: based on LMDI method', China Population, Resources and Environment, 2010, 20 (12), 4-9.

[17]Tu Hongxing, Xiaoxu and Xu Songtao: 'An analysis of carbon dioxide emissions by Chinese industries based on LMDI method', Journal of Central South University, 2014, 20 (4), 31- 36.

[18]Wenwen Wang, Xiao Liu, Ming Zhang and Xuefeng Song: 'Using a new generalized LMDI method to analyze China's energy consumption', Energy, 2014, 67, 617 - 622.

[19]Frédéric Branger and Philippe Quirion: 'Reaping the carbon rent: Abatement and over allocation profits in the European cement industry, insights from an LMDI decomposition analysis', Energy Economics, 2015, 47, 189-205.

[20] National Bureau of Statistics, People Republic of China, China Statistical Yearbook, Beijing, China Statistics Press, 2000-2013.

[21] Department of Energy Statistics, National Bureau of Statistics, China Energy Statistical Yearbook, Beijing, China Statistics Press, 2001-2013.

[22] General Administration of Quality Supervision, Inspection and Quarantine of the People's Republic of China, General principles for calculation of the comprehensive energy consumption (GB/T 2589-2008), Beijing, China Standard Press, 2008.

[23] IPCC, 2008 IPCC Guidelines for National Greenhouse Gas Inventories, 2008, Switzerland.

[24] Shanghai Statistical Bureau, Shanghai Statistical Yearbook, Beijing, China Statistics Press, 2001-2013.

[25] Jiangsu Statistical Bureau, Jiangsu Statistical Yearbook, China Statistical Press, 2001-2013.

[26] Zhejiang Statistical Bureau, Zhejiang Statistical Yearbook, China Statistical Press, 2001-2013.

[27] B. R. Nunlund R, Ghalwash T, Increased energy efficiency and the rebound effect: effect on consumption and emissions, Energy Economics, 2007, 29(1), 1-17. 